\title{
Phase II of the International Study of Asthma and Allergies in Childhood (ISAAC II): rationale and methods
}

\author{
S.K. Weiland*, B. Björkstén\# ${ }^{\#}$, B. Brunekreef ${ }^{\star}$, W.O.C. Cookson ${ }^{+}$, E. von Mutius ${ }^{\S}$, D.P. Strachan ${ }^{f}$, and \\ the International Study of Asthma and Allergies in Childhood Phase II Study Group
}

Phase II of the International Study of Asthma and Allergies in Childhood (ISAAC II): rationale and methods. S.K. Weiland, B. Björkstén, B. Brunekreef, W.O.C. Cookson, E.von Mutius, D.P. Strachan, and the International Study of Asthma and Allergies in Childhood Phase II Study Group. (C) ERS Journals Ltd 2004.

ABSTRACT: International comparative studies, investigating whether disease incidence or prevalence rates differ between populations and, if so, which factors explain the observed differences, have made important contributions to the understanding of disease aetiology in many areas. In Phase I of the International Study of Asthma and Allergies in Childhood (ISAAC), the prevalence rates of symptoms of asthma, allergic rhinitis and atopic eczema in 13-14-yr-olds, assessed by standardised questionnaires, were found to differ $>\mathbf{2 0}$-fold between the $\mathbf{1 5 5}$ study centres around the world. Phase II of ISAAC aims to identify determinants of these differences by studying informative populations.

A detailed study protocol was developed for use in community-based random samples of children aged 9-11 yrs. The study modules include standardised questionnaires with detailed questions on the occurrence and severity of symptoms of asthma, allergic rhinitis and atopic eczema, their clinical management, and a broad range of previous and current exposure conditions. In addition, standardised protocols were applied for examination of flexural dermatitis, skin-prick testing, bronchial challenge with hypertonic saline, blood sampling for immunoglobulin $\mathbf{E}$ analyses and genotyping, and dust sampling for assessment of indoor exposures to allergens and endotoxin.

To date, ISAAC II field work had been completed or started in 30 study centres in 22 countries.

The majority of centres are in countries that participated in International Study of Asthma and Allergies in Childhood Phase $I$ and reflect almost the full range of the observed variability in Phase I prevalence rates.

Eur Respir J 2004; 24: 406-412.
*Dept of Epidemiology, University of Ulm Ulm, and ${ }^{\S}$ Children's Hospital, University of Munich, Munich, Germany. ${ }^{\#}$ Centre for Allergy Research and Institute of Environmental Medicine, Karolinska Institute Stockholm, Stockholm, Sweden. "Institute for Risk Assessment Sciences, University of Utrecht, Utrecht, the Netherlands. "Wellcome Trust Centre for Human Genetics, University of Oxford, Oxford, and ${ }^{f}$ St. Georges's Hospital Medical School, London, UK.

Correspondence: S.K. Weiland, Dept of Epidemiology, University of Ulm, Helmholzstr. 22, 89081 Ulm, Germany.

Fax: 497315031069

E-mail: stephan.weiland@medizin.uni-ulm.de

Keywords: Asthma, childhood, eczema, epidemiology, International Study of Asthma and Allergies in Childhood Phase II, rhinitis

Received: August 52003

Accepted after revision: March 222004

The coordination and central laboratory analyses of the European centres were supported by the Fifth Framework Programme of the European Commission, Brussels, Belgium (QLK4-CT-1999-01288). Support details for the local studies are given in the Funding of local studies section at the end of this article. Pharmacia Diagnostics (Uppsala, Sweden) generously made reagents available at a nominal cost. ALK (Horsholm, Denmark) generously provided reagents for fieldwork in several low-income countries without charge.
International comparative studies, conducted in a standardised way in different populations, have made important contributions to the understanding of disease aetiology in many areas, particularly cardiovascular diseases and cancer [1-5]. They investigate whether disease incidence or prevalence rates differ between populations and, if so, which factors explain the observed differences [1,2].

In the 1990s, two international collaborative studies, one in children [6-10] and one in adults [11-14], chose the international comparative approach in the field of asthma and allergies. Both studies found large differences in prevalence rates between countries, which are likely to be determined to a large extent by environmental or lifestyle factors. Phase I of the International Study of Asthma and Allergies in Childhood (ISAAC I) used standardised written and video questionnaires on the occurrence and severity of symptoms of asthma, allergic rhinitis and atopic eczema, which were completed by children aged 13-14 yrs in 155 centres in 56 countries around the world [7]. The prevalence rates were found to differ $>20$-fold between study centres [7-10]. Phase II of ISAAC (ISAAC II) aims to identify determinants of the observed differences in prevalence rates. For example, the role of atopic sensitisation and bronchial responsiveness, as well as the influence of indoor exposures and lifestyle factors, are being investigated. The study methods are much more demanding than those of ISAAC I and are, therefore, being applied in a smaller, but informative, number of populations, i.e. centres with relatively high or low prevalence rates in ISAAC I or with unusual exposure and living conditions.

\section{Objectives}

The specific objectives of ISAAC II are to assess as follows: 1) the variation in the prevalence and severity of clinical 
symptoms and objective markers of asthma, allergic rhinitis and atopic eczema in children living in different study centres worldwide; 2) the association between potential determinants and the occurrence and severity of asthma and allergies in children in different centres, and to make comparisons between and within study centres worldwide; and 3) the associations of genotypes known or suspected to play a role in childhood asthma and allergies with the measured phenotypes and to investigate gene-gene as well as gene-environment interactions in different study centres worldwide.

\section{Methods}

\section{Study area and population}

ISAAC II studies were conducted in children aged 9-11 yrs. This age group, although different from those studied in ISAAC I (13-14 yrs and 6-7 yrs), was chosen because children aged 10 yrs are known to participate and perform satisfactorily in all of the proposed tests, including spirometry and blood sampling (often problematic in younger children) and examination for flexural dermatitis (problematic in older children in some cultures). Valid measurements of these physiological parameters were considered more important than a direct comparison of age groups with ISAAC I. Study samples were drawn from populations living in defined geographical areas.

\section{Study modules}

The ISAAC II study protocol includes a series of modules that have been developed and agreed by the Steering Committee of the worldwide project $[15,16]$. These modules are freely available for use in other studies, provided that they are strictly adhered to and properly referenced in any resulting publications.

Questionnaires. Standardised core questionnaires were developed on demographics, wheezing, allergic rhinitis and atopic eczema. These include detailed questions on the occurrence and severity of atopic symptoms, identical to those used for parents of children aged 6-7 yrs in ISAAC I [6]. Supplementary questionnaires dealt with additional respiratory symptoms, as well as the clinical management and medical treatment of asthma and wheezing, hay fever, rhinitis and flexural dermatitis. The risk factor questionnaire enquires about current and previous (first year of life) living conditions, and collects information about factors such as birthweight, gestational age, place of birth, socioeconomic status, breast feeding, family size, family history of atopic diseases, infections, vaccinations, crowding, pets, environmental tobacco smoke, cooking fuels, damp housing, type of windows, type of bedding, area of residence, physical activity and nutritional factors. All questionnaires were for completion by parents.

Examination for flexural dermatitis. Participating children were examined for visible flexural dermatitis according to a photographic protocol [17] and detailed instructions on its use in the field. The examination involved inspection of the skin: 1) around the eyes, 2) around the sides and front of the neck, 3 ) in front of the elbows, 4) behind the knees, and 5) in front of the ankles. The presence or absence of signs of visible flexural dermatitis was recorded for each of the five areas. A training package of high-quality clinical photographs and instructions for fieldworkers was developed, which also included a test set of pictures for central evaluation of fieldworker quality [18].
Skin-prick testing for atopy. Extracts of six common aeroallergens (Dermatophagoides pteronyssinus, D. farinae, cat hair, Alternaria tenuis, mixed tree pollen and mixed grass pollen) and control solutions produced by ALK (Hørsholm, Denmark) were used. Cockroach and other allergens of local relevance could be added. Briefly, a drop of each allergen extract and the positive $\left(10 \mathrm{mg} \cdot \mathrm{mL}^{-1}\right.$ histamine $)$ and negative (diluent) control was placed on to the skin of the volar side of the left forearm and pierced vertically using 1-mm ALK lancets. After $15 \mathrm{~min}$, the outer contour of the weal reaction was outlined using a fine felt-tip pen, and the result expressed as the mean of the lengths of the longest diameter and the perpendicular line through its centre. Detailed recommendations for training and monitoring of fieldworkers were provided in order to assess reproducibility and consistency over time.

Bronchial challenge with hypertonic saline. A minimum of two baseline spirograms was recorded, and the higher of two reproducible (within 5\%) measurements of forced expiratory volume in one second (FEV1) was recorded as baseline FEV1. Bronchial reactivity was assessed by changes in FEV1 after inhalation of nebulised saline using an ultrasound nebuliser [19]. The children inhaled hyperosmolar (4.5\%) saline for periods of increasing duration: $0.5,1,2$, 4, and 8 min. FEV1 was measured $1 \mathrm{~min}$ after each inhalation period and the next challenge period followed after $3 \mathrm{~min}$. If the FEV1 fell by $10-15 \%$ from the baseline value, the exposure time was repeated. If, after two repetitions, the FEV1 remained 10-15\% below the baseline value, the duration of the inhalation period was doubled again according to the protocol. Either way, bronchial challenge was stopped if either the FEV1 had fallen by $\geqslant 15 \%$ from baseline or the total inhalation period of $15.5 \mathrm{~min}$ had been reached. The saline canister and tubing were weighed before the first and after the last inhalation period in order to measure the aerosol dose delivered. Participating children were asked to withhold bronchodilator medication before the challenge. Regular use of inhaled steroids was recorded, but not withheld. In children with a baseline FEV1 of $<75 \%$ of the predicted value, no bronchial challenge was performed and an inhaled bronchodilator was administered.

\section{Collaborative laboratory analyses}

Serum samples for analyses of immunoglobulin E. Blood samples were collected by venipuncture into plain sample tubes and allowed to clot at room temperature. The serum was separated by centrifugation $(2,500-3,000$ revolutions per minute for $15 \mathrm{~min}$ ) and pipetted off in 1-mL aliquots into plastic tubes with screw corks. Samples were frozen, stored at $\leqslant-20^{\circ} \mathrm{C}$ and transported under dry ice.

Serum levels of total immunoglobulin (Ig)E and $\operatorname{IgE}$ directed against a panel of common inhalant allergens (Phadiatop ${ }^{\text {TM }}$ ) were quantified using the Pharmacia CAP System $^{\mathrm{TM}}$ (Pharmacia Diagnostics, Uppsala, Sweden). The analyses were performed in one central certified (SWEDAC) laboratory (Dept of Clinical Immunology, Karolinska University Hospital, Stockholm, Sweden). In three centres, analyses had already been performed using the same methods but in another laboratory. The comparability of results obtained in different laboratories was tested in 400 samples from two centres [20], which were analysed in the central laboratory and another laboratory (two laboratories in the case of total $\mathrm{IgE}$ ). There was good agreement between results: for total IgE levels, the concordance correlation coefficient was $>0.99$; and for specific IgE classes, the weighted $\kappa$ was 0.88 . 
Dust samples for analyses of aeroallergens and endotoxins. Instructions for dust collection are in the ISAAC II manual and in the more detailed protocol [21], including photographic instructions, developed by Utrecht University (Utrecht, The Netherlands), which has been in use since 2001. Vacuum cleaners with a $\geqslant 800-\mathrm{W}$ engine were used in combination with ALK filter holders and 70-mm paper filters (ALK or Schleicher\&Schuell, Dassel, Germany). Dust was sampled separately from two sites within homes: the mattress or sleeping place of the index child participating in the study, and the floor in the living room. The beds were vacuumed on the sheets or, if there were no sheets, directly on the mattress or sleeping surface. The original instructions were to vacuum soft surfaces for $2 \mathrm{~min} \cdot \mathrm{m}^{-2}$, covering an area of $\geqslant 2 \mathrm{~m}^{2}\left(\geqslant 4 \mathrm{~m}^{2}\right.$ if possible), and hard surfaces for $1 \mathrm{~min} \cdot \mathrm{m}^{-2}$, covering an area of $\geqslant 4 \mathrm{~m}^{2}$ (ISAAC II manual). This was subsequently made more specific as follows: 1) mattress, whole area for $2 \mathrm{~min}$; 2) carpeted floors, $2 \mathrm{~m}^{2}$ for $4 \mathrm{~min}$; 3) smooth floor with $\geqslant 4-\mathrm{m}^{2}$ rug, $2-\mathrm{m}^{2}$ rug for $4 \mathrm{~min}$; and 4) smooth floor with no rug or smaller $\operatorname{rug}(\mathrm{s}), 4-\mathrm{m}^{2}$ smooth floor for $4 \mathrm{~min}$ (Utrecht University protocol). After collection of dust, the filter box with the filter was removed, the lid was attached and then the box was stored in a plastic bag at $-20^{\circ} \mathrm{C}$ until analysis (ISAAC II manual). Alternatively, after dust collection, the filter with dust was transferred to a preweighed plastic tube directly after the vacuum cleaning, facilitating transport and analysis (Utrecht University protocol).

Laboratory analyses of the dust of European centres took place at Utrecht University, at the Institute for Risk Assessment Sciences. Dust of non-European centres was analysed at the laboratory of the Wellington Asthma Research Group (Wellington School of Medicine and Health Sciences, Wellington, New Zealand). After weighing, floor dust was extracted using Tween-20 in water [22] and analysed for endotoxin, using a kinetic chromogenic Limulus amoebocyte lysate (LAL) test, using only one batch of LAL reagents (LAL lot no. 1L676S and lipopolysaccharide standard lot no. 2L0090; BioWhittaker, Verviers, Belgium) for all ISAAC analyses. Endotoxin concentrations were expressed as units of endotoxin per gram of dust (1 endotoxin unit=0.09 ng). Mattress dust was extracted using phosphatebuffered saline containing $0.05 \%$ Tween-20, and analysed for the allergens $D$. pteronyssinus antigen 1 (Der p 1), D. farinae antigen 1 (Der $\mathrm{f} 1$ ), dog antigen 1 (Can $\mathrm{f} 1$ ) and cat antigen 1 (Fel d 1), using the enzyme immunoassay reagents and methods of Indoor Biotechnologies (Cardiff, UK), essentially as described previously [23]. The lower limits of detection are $8 \mathrm{ng} \cdot \mathrm{mL}^{-1}$ for Der $\mathrm{p} 1,6 \mathrm{ng} \cdot \mathrm{mL}^{-1}$ for Der $\mathrm{f} 1,20 \mathrm{ng} \cdot \mathrm{mL}^{-1}$ for Can f 1 and $0.4 \mathrm{ng} \cdot \mathrm{mL}^{-1}$ for Fel d 1 for five-fold diluted samples. Samples with undetectable amounts of allergen or endotoxin were assigned a value two-thirds that of the lowest observed amount per gram of dust for the specific component determined.

DNA preparation for genotyping. The alternative sources of DNA from study participants included frozen storage of whole blood or buffy coats and storage of whole blood as dried spots. Samples originating from populations with prevalence rates of category III infectious agents (such as hepatitis B and HIV) of $>1 \%$ required extraction in a containment level 3 laboratory.

Whole blood and buffy coat samples were received frozen in tubes containing ethylenediamine tetra-acetic acid, with typical volumes ranging 4-10 mL. Extractions were performed using the Promega Wizard genomic DNA purification kit (Promega UK, Southampton, UK), using the standard protocol adjusted for sample volume. Extraction of blood spots was carried out using the Qiagen Midi Kit (Qiagen,
Crawley, UK). Blood spots were cut from filter paper and further fragmented using autoclaved scissors. Cell lysis and protein precipitation was carried out using volumes adjusted for sample volume.

Following extraction, all samples were quantified using a Molecular Probes Pico Green double-stranded DNA Quantification Kit (Invitrogen, Paisley, UK). Blood spots yielded $0.0-48.0$, buffy coats $0.0-1,013.0$ and whole blood $0.0-578.0 \mathrm{ng} \cdot \mu \mathrm{L}^{-1}$ DNA. The corresponding total amount of DNA from each source was blood spots $0.9-2.1$, buffy coats 3.5-69.5 and whole blood 47.0-69.0 $\mu \mathrm{g}$. Primer extension preamplification was used to increase the quantity of DNA by a factor of 40. This involves using random primer sequences to amplify template DNA, resulting in whole genome amplification [24].

The aim of the genetic module is to genotype the samples with regard to all published genetic polymorphisms associated with childhood asthma and allergies. Several single nucleotide polymorphisms will be typed from each gene in order to create haplotypes that may be compared across populations. Single nucleotide polymorphisms will also be chosen according to their heterozygosity level, with minor allele frequencies of $\geqslant 20 \%$. Genotyping will be carried out using the Sequenom System (Sequenom, Inc., San Diego, CA, USA), which is based on an assay of primer extension with detection by matrix-assisted laser desorption time-of-flight mass spectrometry (MALDI-TOF). Genotyping is performed at the University of Oxford (Oxford, UK).

\section{Sampling options and sample size}

Random samples of $\geqslant 10$ schools had to be chosen from a complete sampling frame of all schools in a defined geographical area. Each centre was expected to provide data on $\geqslant 1,000$ children with completed parental questionnaires, examination for flexural dermatitis and skin-prick tests for atopy. Measurement of bronchial responsiveness and collection of blood and dust samples were performed in stratified subsamples. These consisted of $\geqslant 100$ children chosen at random from those with a history of wheeze in the past year and $\geqslant 100$ children selected at random from all those without wheeze in the past year (option B). This stratified sampling procedure substantially reduced the costs in comparison to testing the entire sample of children. It permits comparisons between centres of objective markers of asthma and atopy, such as bronchial responsiveness and total or specific serum IgE levels. At the discretion of local investigators, all tests could be performed on all participants (option A).

It was calculated that this sample size and sampling procedure (option B) would permit detection (with $95 \%$ confidence) of prevalence differences between two centres with $80 \%$ power at the following magnitude: wheezing 6 versus $10 \%$ (90\% power); severe wheezing 1 versus $3 \%$; atopic sensitisation 15 versus $20 \%$; flexural dermatitis 2.5 versus $5 \%$; and bronchial hyperresponsiveness 20 versus $40 \%$.

\section{Quality control}

Major efforts were made to ensure comparable data quality in all study centres. A standardised study protocol was developed, which gave very detailed instructions for all study procedures. It provided detailed guidance for the training of fieldworkers, and some elements were centrally evaluated, e.g. skin examination for dermatitis. In addition, close collaboration and visits between study centres was encouraged and occurred throughout the study. There was a central 
3-day workshop for training in ISAAC II methods at the University of Münster (Münster, Germany) in March 1998, at which almost all countries participating in ISAAC II were represented (exceptions were West Bank, Ghana and Ecuador). There were many visits of experienced collaborators to other study centres to train fieldworkers or monitor fieldwork. Relevant aspects of fieldwork were recorded and reported to the data centre. The analyses were carried out in central laboratories in Oxford, Stockholm, Wellington and Utrecht.

\section{Data management and statistical analyses}

All data from fieldwork and laboratory analyses were collated by the ISAAC II Coordinating and Data Centre at the University of Ulm (Ulm, Germany). The study centres submitted their data according to the coding and transfer manual, which provides detailed guidance. Prevalence rates will be calculated and associations of health outcomes with potential determinants will be investigated using bivariate and multivariate techniques. Data collected only in stratified subsamples (option B) will be analysed taking the sampling structure into account $[25,26]$.

\section{Participating study centres}

To date, ISAAC II fieldwork has been completed or started in 30 study centres in 22 countries (table 1). The data from 24 study centres have been accepted by the Coordinating and Data Centre in Ulm.

ISAAC II focused on "informative" populations, usually identified on the basis of ISAAC I findings [7-10]. The countries included in ISAAC II reflect almost the full range of variability in asthma prevalence rates observed in ISAAC I (fig. 1). Thus, countries which were ranked at the top (e.g. UK and New Zealand) or bottom (e.g. Albania, Georgia and India) of the worldwide distribution of prevalence rates

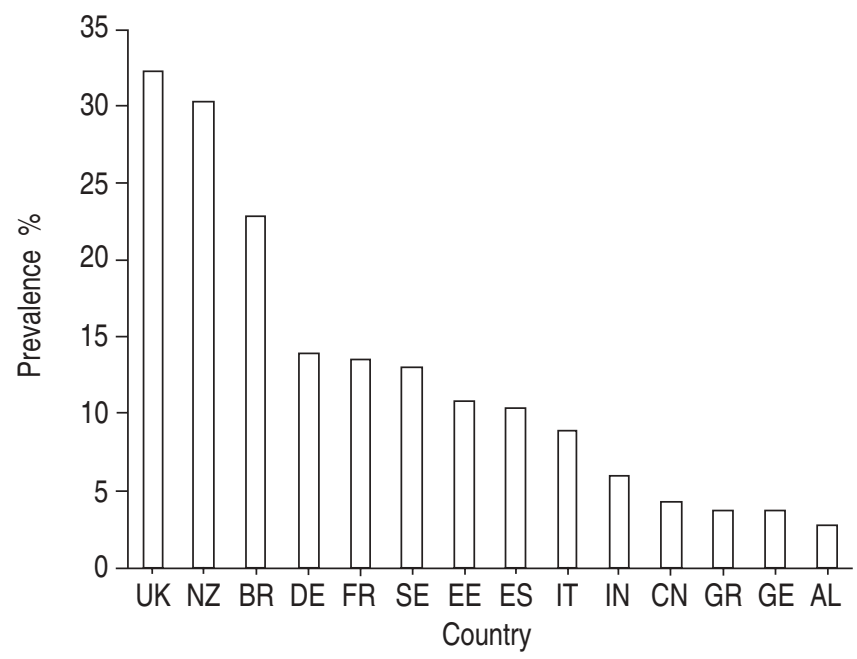

Fig. 1.-Mean 12-month wheeze prevalence obtained in the 13-14 yrs age group in the International Study of Asthma and Allergies in Childhood (ISAAC) Phase I in countries participating in ISAAC Phase II [9]. NZ: New Zealand; BR: Brazil; DE: Germany; FR: France; SE: Sweden; EE: Estonia; ES: Spain; IT: Italy; IN: India; CN: China; GR: Greece; GE: Georgia; AL: Albania.

Table 1. - Current status of International Study of Asthma and Allergies in Childhood Phase II (ISAAC II) data collection

\begin{tabular}{|c|c|c|c|c|}
\hline Country & Centre & Sampling option & Fieldwork complete & Checking complete ${ }^{\#}$ \\
\hline Albania & Tirana & $\mathrm{B}$ & $\mathrm{Y}$ & $\mathrm{Y}$ \\
\hline Brazil & Pôrto Alegre & B & $\mathrm{N}$ & $\mathrm{N}$ \\
\hline \multirow[t]{3}{*}{ China } & Beijing & B & $\mathrm{Y}$ & $\mathrm{Y}$ \\
\hline & Guangzhou & $\mathrm{B}$ & $\mathrm{Y}$ & $\mathrm{Y}$ \\
\hline & Hong Kong & B & $\mathrm{Y}$ & $\mathrm{Y}$ \\
\hline Ecuador & Pichincha province & A & $\mathrm{Y}$ & $\mathrm{N}$ \\
\hline Estonia & Tallinn & B & $\mathrm{Y}$ & $\mathrm{Y}$ \\
\hline France & Créteil & B & $\mathrm{N}$ & $\mathrm{N}$ \\
\hline Georgia & Tbilisi & $\mathrm{B}$ & $\mathrm{Y}$ & $\mathrm{Y}$ \\
\hline \multirow[t]{2}{*}{ Germany } & Dresden & A & $\mathrm{Y}$ & $\mathrm{Y}$ \\
\hline & Munich & A & $\mathrm{Y}$ & $\mathrm{Y}$ \\
\hline Ghana & Kintampo & B & $\mathrm{Y}$ & $\mathrm{Y}$ \\
\hline \multirow[t]{2}{*}{ Greece } & Athens & B & $\mathrm{Y}$ & $\mathrm{Y}$ \\
\hline & Thessaloníki & B & $\mathrm{Y}$ & $\mathrm{Y}$ \\
\hline Iceland & Reykjavík & B & $\mathrm{N}$ & $\mathrm{N}$ \\
\hline India & Mumbai & B & $\mathrm{Y}$ & $\mathrm{N}$ \\
\hline Italy & Rome & B & $\mathrm{Y}$ & $\mathrm{Y}$ \\
\hline Latvia & Riga & A & $\mathrm{Y}$ & $\mathrm{N}$ \\
\hline The Netherlands & Utrecht & A & $\mathrm{Y}$ & $\mathrm{Y}$ \\
\hline New Zealand & Hastings & B & $\mathrm{Y}$ & $\mathrm{Y}$ \\
\hline Norway & Tromsø & B & $\mathrm{Y}$ & $\mathrm{Y}$ \\
\hline \multirow[t]{4}{*}{ Spain } & Almeria & $\mathrm{B}$ & $\mathrm{Y}$ & $\mathrm{Y}$ \\
\hline & Cartagena & B & $\mathrm{Y}$ & $\mathrm{Y}$ \\
\hline & Madrid & $\mathrm{B}$ & $\mathrm{Y}$ & $\mathrm{Y}$ \\
\hline & Valencia & B & $\mathrm{Y}$ & $\mathrm{Y}$ \\
\hline \multirow[t]{2}{*}{ Sweden } & Linköping & $\mathrm{B}$ & $\mathrm{Y}$ & $\mathrm{Y}$ \\
\hline & Östersund & $\mathrm{B}$ & $\mathrm{Y}$ & $\mathrm{Y}$ \\
\hline Turkey & Ankara & B & $\mathrm{Y}$ & $\mathrm{Y}$ \\
\hline UK & West Sussex & B & $\mathrm{Y}$ & $\mathrm{Y}$ \\
\hline West Bank & Ramallah & B & $\mathrm{Y}$ & $\mathrm{Y}$ \\
\hline
\end{tabular}

B: some tests performed in stratified subsample of wheezers and nonwheezers; A: tests performed in all children; Y: yes; N: no. ${ }^{\#}$ : data checking carried out by ISAAC II Coordinating and Data Centre, Dept of Epidemiology, University of Ulm, Ulm, Germany. 


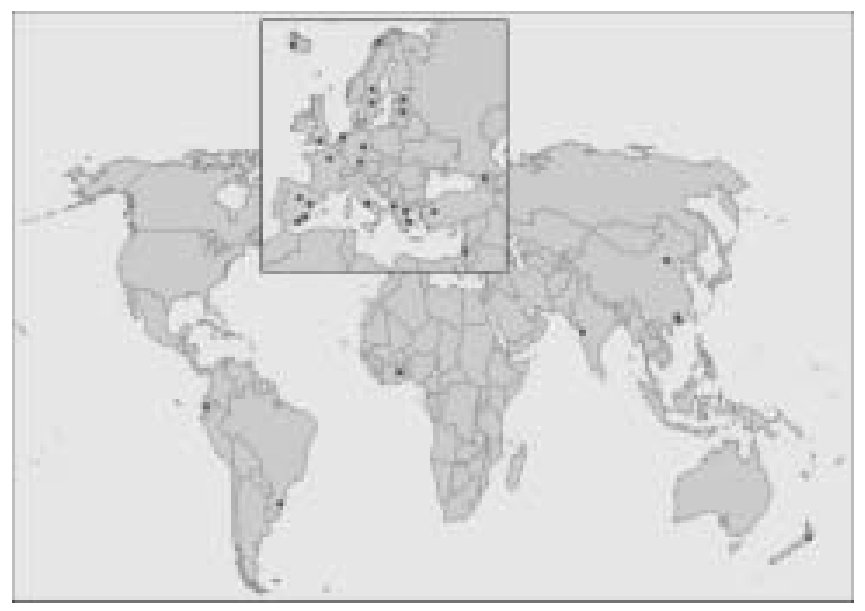

Fig. 2. - Location of study centres ( $\boldsymbol{\square})$ at which International Study of Asthma and Allergies in Childhood Phase II fieldwork is ongoing or complete.

are represented in ISAAC II. The location of the study centres is shown in figure 2. Additional centres, which have been included due to interesting exposure and living conditions, are located in Ecuador, Ghana, Iceland, Norway, Turkey and West Bank.

\section{Organisational structure}

ISAAC II is managed by the ISAAC II Steering Group and by subcommittees who deal with specific aspects of the study. All members of the ISAAC II Steering Group are also members of the ISAAC Steering Committee. ISAAC II study centres in countries with more than one centre are coordinated by National Coordinators. All studies have been approved by local ethics committees, and the international coordination and collaboration has been approved by the ethics committees of the universities of Münster and Ulm, Germany.

\section{Outlook}

The International Study of Asthma and Allergies in Childhood Phase II will be the most comprehensive study of the prevalence, risk factors, and genetics of asthma and allergies in children yet undertaken. The wide range of ethnicities, environments, lifestyles, and climatic and socioeconomic conditions amongst the $>30,000$ children who have taken part in the International Study of Asthma and Allergies in Childhood Phase II will provide a unique cross-sectional view of the determinants of asthma and allergic disease and potentially the interactions between environmental and genetic factors.
G.Weinmayr (Dept of Epidemiology, University of Ulm, Ulm, Germany).

Principal Investigators and Scientific Team: Tirana, Albania: A. Priftanji, A. Shkurti, J. Simenati, E. Grabocka, K. Shyti, S. Agolli and A. Gurakuqi; Pôrto Alegre, Brazil: R.T. Stein, M. Urrutia de Pereira, M.H. Jones and P.M. Pitrez; Bejing, China: Y.Z. Chen; Guangzhou, China: N.S. Zhong; Hong Kong, China: C. Lai (National Coordinator) and G. Wong; Pichincha province, Ecuador: P.J. Cooper and M. Chico; Tallinn, Estonia: M-A. Riikjärv and T. Annus; Créteil, France: I. Annesi-Maesano; Tbilisi, Georgia: M. Gotua, M. Rukhadze, T. Abramidze, I. Kvachadze, L. Karsanidze, M. Kiladze and N. Dolidze; Dresden, Germany: W. Leupold, U. Keil, E. von Mutius and S.K. Weiland; Munich, Germany: E. von Mutius, U. Keil and S.K. Weiland; Kintampo, Ghana: P. Arthur (deceased) and E. Addo-Yobo; Athens, Greece: C. Gratziou (National Coordinator), C. Priftis, A. Papadopoulou and C. Katsardis; Thessaloniki, Greece: J. Tsanakas, E. Hatziagorou and F. Kirvassilis; Reykjavik, Iceland: M. Clausen; Mumbai, India: J.R. Shah, R.S. Mathur, R.P. Khubchandani and S. Mantri; Rome, Italy: $\mathrm{F}$. Forastiere, R. Di Domenicantonio, M. De Sario, S. Sammarro, R. Pistelli, M.G. Serra, G. Corbo and C.A. Perucci; Riga, Latvia: V. Svabe, D. Sebre, G. Casno, I. Novikova and L. Bagrade; Utrecht, the Netherlands: B. Brunekreef, D. Schram, G. Doekes, P.H.N. Jansen-van Vliet, N.A.H. Janssen, F.J.H. Aarts and G. de Meer; Hastings, New Zealand: J. Crane, K. Wickens and D. Barry; Tromsø, Norway: W. Nystad, R. Bolle and E. Lund; Almeria, Spain: J. Batlles Garrido, T. Rubi Ruiz, A. Bonillo Perales, Y. Gonzalez Jiménez, J. Aguirre Rodriguez, J. Momblan de Cabo, A. Losilla Maldonado and M. Daza Torres; Cartagena, Spain: L. Garcia-Marcos (National Coordinator), A. Martinez Torres, J.J. Guillén Pérez, A. Piñana López and S. Castejon Robles; Madrid, Spain: G. Garcia Hernandez, A. Martinez Gimeno, A.L. Moro Rodríguez, C. Luna Paredes and I. Gonzalez Gil; Valencia, Spain. M.M. Morales Suarez-Varela, A. Llopis González, A. Escribano Montaner and M. Tallon Guerola; Linköping, Sweden: L. Bråbäck (National Coordinator), B. Björkstén, M. Kjellman, L. Nilsson and X-M. Mai; Östersund, Sweden: L. Bråbäck and A. Sandin; Ankara, Turkey: Y. Saraçlar, S. Kuyucu, A. Tuncer, C. Saçkesen, V. Sumbuloğlu, P. Geyik and C. Kocabaş; West Sussex, UK: D. Strachan and B. Kaur; Ramallah, West Bank: N. El-Sharif, B. Nemery, F. Barghuthy, S. Abu Huij and M. Qlebo.

Laboratories: Blood samples were analysed for serum $\operatorname{IgE}$ levels at the Karolinska Institute, Stockholm, Sweden (B. Björkstén and M. van Hage-Hamsten). DNA analyses were performed at the Wellcome Trust Centre for Human Genetics, University of Oxford, Oxford, UK (W. Cookson, M. Moffatt and J. Cantelmo). Analyses of dust samples were carried out at the Institute for Risk Assessment Sciences, University of Utrecht, Utrecht, the Netherlands (B. Brunekreef, D. Schram, M. Boeve-Wietzes, G. Doekes, G. Terpstra, J. Spithoven and S. de Wind), and by the Wellington Asthma Research Group, Wellington School of Medicine and Health Sciences, Wellington, New Zealand (J. Crane and R. Siebers).

ISAAC Steering Committee: N. Ait-Khaled (Paris, France), H.R. Anderson (London, UK), E. Mitchell (Auckland, New Zealand), I. Asher (Auckland, New Zealand), S. Montefort (Guardamangia, Malta), R. Beasley (Wellington, New Zealand), J. Odhiambo (Nairobi, Kenya), B. 
Björkstén (Stockholm, Sweden), N. Pearce (Wellington, New Zealand), B. Brunekreef (Utrecht, the Netherlands), C. Robertson (Parkville, Australia), W. Cookson (Oxford, UK), J. Shah (Mumbai, India), J. Crane (Wellington, New Zealand), A. Stewart (Auckland, New Zealand), P. Ellwood (Auckland, New Zealand), D. Strachan (London, UK), S. Foliaki (Wellington, New Zealand), E. von Mutius (Munich, Germany), U. Keil (Münster, Germany), S.K. Weiland (Ulm, Germany), C. Lai (Shatin, Hong Kong), H. Williams (Nottingham, UK) and J. Mallol (Santiago, Chile).

Module coordinators: ISAAC II modules have been developed by subgroups of members of the Steering Committee. Coordinators: M. Burr (additional respiratory questions); C. Robertson (questions on disease management); S.K. Weiland (risk factor questionnaire); H.C. Williams (examination for flexural dermatitis); E. von Mutius (skin-prick test and serum IgE); C. Robertson (bronchial responsiveness to hypertonic saline); B. Björkstén (blood sampling and frozen storage).

Funding of local studies: Almeria: Fondo de Investigacion Sanitaria (grant code 00/1092E); Ankara*: Scientific and Technical Research council of Turkey (grant code SPAG-2237), Treatment and Research Foundation of Turkey for Allergy, Asthma and Immunology, and the Research Foundation of Hacettepe University Faculty of Medicine; Athens: the Thorax Foundation Research Centre, Greece; Cartagena: Fondo de Investigacion Sanitaria (grant code 00/1092E). Créteil: French Institute of Health and Medical Research (Institut National de la Santé et de la Recherche Médicale (INSERM)) (grant codes IDS 337/4D001D and 737/69480), Ministère de l'Emploi et de la Solidarité (grant code 227/7HL02D), Mutuelle Générale de 1'Education Nationale (grant code 257/8PL01F) and Agence de $1^{\prime}$ Environnement et de la Maitrise de $1^{\prime}$ Energie ADEME/PRIMEQUAL 96 (grant code FJ012B); Dresden: German Ministry of Education and Research (01 EE 9411-3); Hastings: Health Research Council of New Zealand, Asthma and Respiratory Foundation of New Zealand, and Hawkes Bay Medical Research Foundation; Kintampo*: Linköping: the Swedish Foundation for Health Care Sciences and Allergy Research; Madrid: Fondo de Investigacion Sanitaria (grant code 00/1092E); Mumbai*: Jaslok Hospital \& Research Centre; Munich: German Ministry of Education and Research (01 EE 9411-3); Östersund: the Swedish Foundation for Health Care Sciences and Allergy Research; Pichincha province: Wellcome Trust; Porto Alegre: Rudolf und Clothilde Eberhardt Foundation, Ulm, Germany; Ramallah: Al-Quds University, Directorate General for International Cooperation and Belgian Technical Cooperation; Riga*; Rome: Lazio Regional Health Authority; Tallinn*; Tbilisi*; Thessaloniki: the Thorax Foundation Research Centre, Greece; Tirana*; Utrecht: Dutch Ministries of the Environment, of Health and of Transport, Rotterdam, the Netherlands; Valencia: Fondo de Investigacion Sanitaria (grant code 00/1092E); West Sussex: South Thames National Health Service Regional Research and Development project SPGS 573. *: centres supported, at least in part, by European members of the ISAAC Steering Committee.

\section{References}

1. G. Rose. The Strategy of Prevention. Oxford, Oxford University Press, 1992.
2. Marmot MG. Improvement of social environment to improve health. Lancet 1998; 351: 57-60.

3. van den Hoogen PC, Feskens EJ, Nagelkerke NJ, Menotti A, Nissinen A, Kromhout D. The relation between blood pressure and mortality due to coronary heart disease among men in different parts of the world. N Engl J Med 2000; 342: 1-8.

4. Wolf-Maier K, Cooper RS, Banegas JR, et al. Hypertension prevalence and blood pressure levels in 6 European countries, Canada, and the United States. JAMA 2003; 289: 2363-2369.

5. Parkin DM, Whelan SL, Ferlay J, Teppo L, Thomas DB, eds. Cancer incidence in five continents. Vol. 8. International Agency for Research on Cancer Scientific Publication no. 155. Lyon, IARC Press, 2002; pp. 1-781.

6. Asher MI, Keil U, Anderson HR, et al. International Study of Asthma and Allergies (ISAAC): rationale and methods. Eur Respir J 1995; 8: 483-491.

7. Strachan D, Sibbald B, Weiland SK, et al. Worldwide variation in prevalence of symptoms of allergic rhinoconjunctivitis in children: the International Study of Asthma and Allergies in Childhood (ISAAC). Pediatr Allergy Immunol 1997; 8: 161-176.

8. The International Study of Asthma and Allergies in Childhood (ISAAC) Steering Committee. Worldwide variation in prevalence of symptoms of asthma, allergic rhinoconjunctivitis and atopic eczema: the International Study of Asthma and Allergies in Childhood (ISAAC). Lancet 1998; 351: $1225-1232$.

9. The International Study of Asthma and Allergies in Childhood (ISAAC) Steering Committee. Worldwide variations in the prevalence of asthma symptoms: the International Study of Asthma and Allergies in Childhood (ISAAC). Eur Respir $J$ 1998; 12: 315-335.

10. Williams H, Robertson C, Stewart A, et al. Worldwide variations in prevalence of symptoms of atopic eczema in the International Study of Asthma and Allergies in Childhood. J Allergy Clin Immunol 1999; 103: 125-138.

11. Pearce N, Sunyer J, Cheng S, et al. Comparison of asthma prevalence in the ISAAC and the ECRHS. Eur Respir $J$ 2000; 16: 420-426.

12. Burney PG, Luczynska C, Chinn S, Jarvis D. The European Community Respiratory Health Survey. Eur Respir J 1994; 7: 954-960.

13. Janson C, Anto J, Burney $\mathrm{P}$, et al. The European Community Respiratory Health Survey: what are the main results so far? Eur Respir J 2001; 18: 598-611.

14. European Community Respiratory Health Survey II Steering Committee. The European Community Respiratory Health Survey II. Eur Respir J 2002; 20: 1071-1079.

15. University of Auckland. International Study of Asthma and Allergies in Childhood (ISAAC). http://isaac.auckland.ac.nz. Date last updated: 18 May 2004. Date last accessed: 16 June 2004.

16. Dept of Epidemiology, University of Ulm. International Study of Asthma and Allergies in Childhood Phase II. www.uni-ulm.de/epidemiologie/ISAACII. Date last updated: 14 June 2004. Date last accessed: 16 June 2004.

17. Williams HC, Forsdyke H, Boodoo G, Hay RJ, Burney PGJ. A protocol for recording the sign of visible flexural dermatitis. Br J Dermatol 1995; 133: 941-949.

18. Williams HC. So How Do I Define Atopic Eczema? A Practical Manual for Researchers Wishing to Define Atopic Eczema. www.nottingham.ac.uk/dermatology/eczema/. Date last updated: November 1996. Date last accessed: 15 June 2004.

19. Riedler J, Reade T, Dalton M, Holst D, Robertson C. Hypertonic saline challenge in an epidemiologic survey of asthma in children. Am J Respir Crit Care Med 1994; 150: 1632-1639.

20. Weiland SK, von Mutius E, Hirsch T, et al. Prevalence of respiratory and atopic disorders among children in the East and West of Germany five years after unification. Eur Respir $J$ 1999; 14: 862-870. 
21. Institute for Risk Assessment Sciences, University of Utrecht. www.iras.uu.nl. Date last updated: 31 March 2004.

22. Douwes J, Versloot P, Hollander A, Heederik D, Doekes G. Influence of various dust sampling and extraction methods on the measurement of airborne endotoxin. Appl Environ Microbiol 1995; 61: 1763-1769.

23. van Strien RT, Koopman LP, Kerkhof M, et al. Mite and pet allergen levels in homes of children born to allergic and nonallergic parents: the PIAMA study. Environ Health Perspect 2002; 110: 693-698.
24. Zhang L, Cui X, Schmitt K, Hubert R, Navidi W, Arnheim $\mathrm{N}$. Whole genome amplification from a single cell: implications for genetic analysis. Proc Natl Acad Sci USA 1992; 89: $5847-5851$.

25. Chambless LE, Boyle KE. Maximum likelihood methods for complex sample data: logistic regression and discrete proportional hazards models. Commun Stat Theory Methods 1985; 14: 1377-1392.

26. Pfeffermann D. The role of sampling weights when modeling survey data. Int Stat Rev 1993; 61: 317-337. 